\title{
A qualitative analysis of patients' perception of microwave endometrial ablation as a satisfactory treatment for heavy menstrual blood loss
}

Received: 3 June 2005 / Accepted: 26 December 2005 / Published online: 17 October 2006

(C) Springer-Verlag Berlin / Heidelberg 2006

\begin{abstract}
To explore and analyse patients' views and comments on microwave endometrial ablation (MEA), we designed a simple and concise questionnaire of 10 items that the participants answered by ticking boxes. They were invited to add their own comments and opinions if they wished. The questionnaire survey was posted to 470 patients who were treated with MEA at Derriford Hospital between 1997 and 2003. We received replies from 343 patients $(73 \%)$, of whom 165 included handwritten comments (48\%). These were reviewed using content thematic analysis. This paper describes the findings of this analysis. Of the 343 respondents, 127 expressed their satisfaction, 32 would recommend MEA to others, and 17 claimed that MEA had transformed their lives. They used words such as "delighted," "grateful," "fantastic," "I cannot tell you how wonderful it has been," "freedom at last," "I feel so much better within myself," "I cannot begin to describe the feelings of well-being and relief I have experienced since I had this treatment," and "it has changed my life from being housebound to never giving my periods a thought." Thirty-eight patients were not satisfied; of these, 14 were experiencing moderate to severe pain, and
\end{abstract}

Shortly after this paper was submitted, Emad Louis tragically died from complications following surgery, whilst waiting to take up his post as a Consultant at St. Mary's Hospital, Isle of Wight. We remember him with great affection as a wonderful colleague, who is held in the highest regard by his patients and all who worked with him. He is greatly missed.

He leaves a wife and son who are enormously proud that his research has been published.

P. Gardiner

Health Sciences Research, RDSU, Room N17, ITTC Building, Peninsula Medical School,

Tamar Science Park, Research Way,

Plymouth, PL6 8BX, UK

E. Louis - N. Elkington .

J. Frappell $(\bowtie) \cdot$ J. Morsman

Department of Obstetrics and Gynaecology,

Level 7 Medical Administration, Derriford Hospital,

Plymouth, PL6 8DH, UK

e-mail: jonathanfrappell@phnt.swest.nhs.uk six claimed to have developed severe pain de novo. Their comments included "I was disappointed MEA did not work for me" and "I get heavy bleeding and pain each month, [whereas] before I had no period pains at all." In conclusion, MEA has been a "miracle cure" for many women who responded, with around $77 \%$ being satisfied with this treatment. For a small number, MEA was not successful. For some women, pain was a problem that either developed de novo or was preexisting in the form of dysmenorrhoea. In this paper we also mention success rates and figures from quantitative studies, and we recommend including quotes from satisfied patients in patient information leaflets to further help women and their physicians make informed choices about managing heavy menstrual blood loss, particularly when medical treatment is known to be less successful and with some women being concerned about its side effects.

Keywords Microwave Endometrial Ablation .

Patient satisfaction - Assessment of subjective symptoms

\section{Introduction}

In routine clinical practice, the diagnosis of heavy menstrual blood loss is based on the woman's subjective assessment. Women often seek treatment when the perceived heavy menstrual loss has a negative impact on work attendance, social activities, sex, and holidays, although the measured loss may well be within the normal range [1].

Women should be offered a choice of medical treatment, which include antifibrinolytic drugs, nonsteroidal antiinflammatory drugs, combined oral contraceptive pills $[2,3]$, the levonorgestrel-releasing intrauterine system $[4,5]$, and endometrial ablation as an alternative to hysterectomy.

Second-generation endometrial ablation technology such as microwave endometrial ablation (MEA) was developed to provide a simple and rapid procedure that is easy to learn and safe to perform $[6,7]$. 
The only guarantee of amenorrhoea is hysterectomy, which, despite being a far more invasive procedure, has a high rate of patient satisfaction. However, about half of all women treated with hysterectomy for heavy menstrual loss have a normal uterus removed [8]; they would have been suitable candidates for MEA.

Women's perceptions of satisfactory resolution of heavy menstrual blood loss should be explored further because the aim of endometrial ablation is not to achieve total cessation of menstruation but to restore menstrual bleeding to an acceptable level.

For this reason, qualitative research and follow-up of long-term patient satisfaction-i.e. improvement of the symptoms together with the absence of complicationsis important.
Fig. 1 Questionnaire
Microwave Endometrial Ablation (MEA) Follow-up Survey

(Please tick boxes)

Age at time of MEA

Under 30

45-49

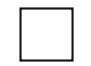

30-34

50-54

4

$55-59$

35-39

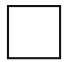

40-44

Overall are you satisfied with the result of your MEA treatment?

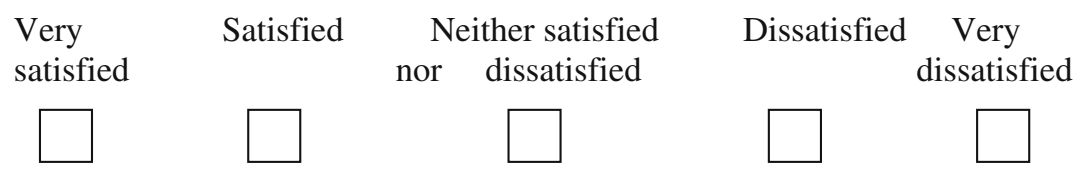

Before MEA treatment my periods were:

\begin{tabular}{|c|c|c|c|c|}
\hline Very heavy & Heavy & Normal & Light & Very \\
\hline
\end{tabular}

After MEA treatment my periods were:

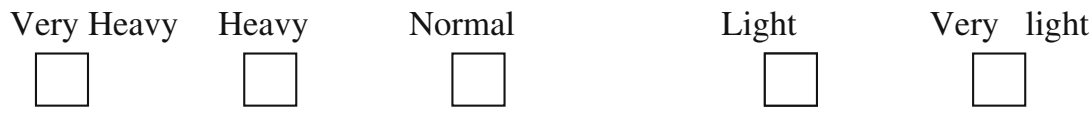

How many months after MEA treatment did your periods stop?

months

If your periods have not stopped are they: Better

Worse

Before MEA treatment did you have painful periods?

Very painful

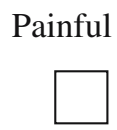

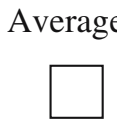

Painless

After MEA treatment my periods were:

Very painful
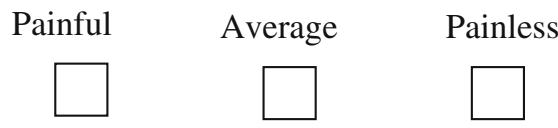
Fig. 1 (continued)

Since your MEA treatment, have you had:

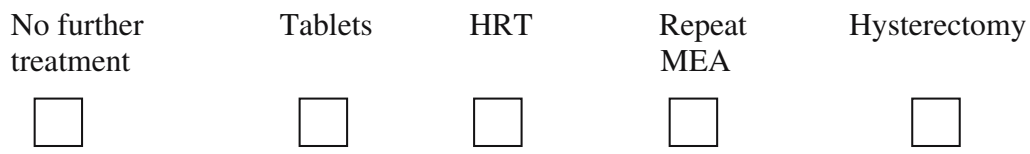

If you have had a hysterectomy following MEA treatment was it due to persistence of heavy periods / pain?

Yes

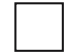

What type of contraception are you using?

None

Not sexually active

Condoms

Combined oral contraceptive pill

Mini pill

Depot injection

Coil

Diaphragm

Female sterilization

Male sterilization

Other

Comments:

We are very interested in your opinions and views. Please use the reverse of this form for any further comments that you wish to make.

Please return the questionnaire in the stamped addressed envelope. Many Thanks.

\section{Method}

We designed a questionnaire survey, which was posted to all the patients who were treated at Derriford Hospital, Plymouth, between 1997 and 2003. The South West Devon Research Ethics Committee approved the study. The questionnaire consisted of 10 items (Fig. 1), which the participants answered by ticking boxes. The design was simple and concise to encourage a high response. At the end of the questionnaire, participants were invited to add their own comments and opinions if they wished.

We sent out 470 questionnaires, of which 343 were returned (73\% response rate). Among those who responded, 165 included handwritten comments $(48 \%)$. These were reviewed using content thematic analysis. This paper describes the findings from these comments.

\section{Results}

Of the 343 respondents, 127 (77\%) expressed their satisfaction with MEA. Among them, 31 stated they would recommend this treatment to other women experiencing similar problems, and 17 claimed that MEA had transformed their lives.

Thirty-eight $(23 \%)$ respondents commented that they were dissatisfied with the results of MEA. Among them, 14 were experiencing moderate to severe pain, and 12 were suffering from other effects.

Twenty-eight respondents described how their lives had been before MEA, and 17 commented on aspects related to the treatment itself, the day of the operation, and the immediate postoperative period. Thirteen other comments could not be categorised but are worth relating.

All comments are described in more detail below. 


\section{Before MEA}

Twenty-eight respondents described their heavy, prolonged, and/or painful periods and the effects these had on their lives: "I had years of heavy periods, clotting, and flooding," "I had heavy blood loss and anaemia," "I was in agony for at least 10 days per month with uncontrollable heavy periods."

Some respondents described periods lasting up to 3 weeks or with only a few days between each one. They were unable to work or even to go out: "Before this treatment I lost over a week each month."

Other effects of heavy blood loss commonly included comments describing anaemia, feelings of being "tired" or "totally drained," and the need to take "tablets almost constantly."

One respondent described how she used to sit on carrier bags to prevent leaks from spoiling the furniture.

For a number of respondents, heavy periods had "ruled their lives"; other such comments included "I went through hell" and "heavy periods made everyday living a problem."

\section{MEA procedure}

Seventeen women commented on the procedure itself, seven positively and 10 negatively. The operation was described by some as "a very simple procedure" and "relatively painless," with one respondent stating "I could hardly believe such a quick minor operation could sort out a major problem."

Four described the procedure as "very painful," two "needed at least 2 weeks to recover," and another two felt they had been sent home too early ("with hindsight, I would have stayed in hospital that night").

Two were pleased with their postoperative care: "All the healthcare professionals were really helpful and reassuring -made a difficult day much more bearable"; however, one felt that "the postoperative care in a busy ward was inappropriate and unhelpful."

A small number complained about the inadequate level of follow-up.

\section{Effectiveness of MEA}

Fifty-two respondents specifically commented on how effective MEA had been in resolving their problem. Among them, 31 now had lighter or absent periods, 12 still had heavy periods, and a small number found that the treatment had been a success initially, but then their periods started to get heavier again. Three respondents mentioned that although their periods were lighter, they had become more painful.
Satisfaction with treatment

A total of 127 expressed their general satisfaction with the results of MEA, using words such as "delighted," "grateful," "fantastic," "I cannot tell you how wonderful it has been," and "freedom at last!"

Five described MEA favourably compared with needing hysterectomy, indicating that they were glad to have been able to avoid the latter.

These comments have been grouped into subcategories:

- General health:

Eight respondents felt that their general health was better since having MEA. This may have been due to improvement of anaemia but was probably also due to psychological factors. Several commented on their previous worry about blood loss and the subsequent feeling of freedom: "I feel so much better within myself," "I can't begin to describe the feelings of wellbeing and relief I have experienced since I had this treatment."

- Life-changing treatment:

Twenty-nine respondents claimed that having MEA had transformed their lives or had restored their lives to normal. "It's made such a difference to my life" was a typical comment; other respondents were more specific: "It changed my life from being housebound to never giving my periods a thought."

- Recommendation to others:

Thirty-two respondents mentioned that they would recommend MEA to others experiencing heavy and painful periods. Several had already advocated the operation to friends. Three wished that MEA had been available years ago. Another expressed her hope that MEA will be offered to more patients in the future.

\section{Dissatisfaction with treatment}

Although the majority of respondents were very satisfied, $38(23 \%)$ expressed some degree of dissatisfaction in their comments.

For 14, moderate to severe pain after MEA was a serious problem. Among them, eight had experienced painful periods before treatment and were hoping that this would be resolved. More important is the fact that six respondents claimed to have developed severe pain, which they had not experienced before the operation: "I get heavy bleeding and pain each month, [whereas] before I had no period pains at all."

Eight respondents expressed general dissatisfaction: "I was disappointed MEA did not work for me." Four had had repeat MEA and were still dissatisfied, and three went on to have hysterectomy. Eleven had noticed the gradual recurrence of their original symptoms: "After 2 years, I get pains and bleeding if I do any lifting or strenuous exercise." 
Unrelated events attributed to treatment

Six respondents claimed that the operation had resulted in their putting on between half a stone and one-and-a-half stone in weight. Four mentioned that they became very bloated. One, on the other hand, had lost a significant amount of weight. Two had constant vaginal discharge, and another two described "having contracted long-term infection following surgery." A further two had suffered from hot flushes since the treatment: "I get bad sweats and flushes all the time, [but] I am only 35 [so] it can't be the menopause." One respondent mentioned that she had developed high blood pressure since the operation, while another stated that following treatment her raised blood pressure was restored to normal levels. One respondent claimed that MEA had cost her her sex drive.

\section{Discussion}

Patient satisfaction is a subjective concept related to patient characteristics such as age, education, social class, and health [9]. Moreover, the symptom of heavy menstrual blood loss is notoriously subjective, and the loss is perceived to be heavier when it is associated with pain [10]. We know from research that objectively confirmed diagnosis is more likely to be associated with a higher treatment success rate than when the treatment is offered on the basis of a subjective diagnosis [11]. Also, around onethird of women have a strong preference towards a particular treatment option [12].

We felt that by reporting the patients' own comments, a different insight into the perception of the problem and its magnitude can be presented, as well as truly reflecting the impact of treatment as seen through the eyes of the service users. This is important because it depicts themes and highlights consistencies in opinion, which are not given much emphasis in the commonly used outcome scales such as the menorrhagia outcome questionnaires [13], the multiattribute questionnaire [14], the generic measure of quality of life [15], or the short form with 36 items (SF-36).

For many women in our study, MEA may be a "miracle cure." Around $77 \%$ are still satisfied with the success achieved by this treatment. The satisfaction noted in this study related not only to improved physical health but also to psychological benefits and feelings of release or even transformation.

This survey also revealed a number of comments relating to dissatisfaction. It is recognised that openended questions often produce a disproportionate level of negative responses, respondents sometimes perceiving this as a legitimate channel for their complaints [16].

For a small number, MEA was not successful. Although initial follow-up after MEA revealed a hysterectomy rate of $10 \%$ after 2 years, this rose to $25 \%$ after 5 years [17]. Longer follow-up might reveal an even higher failure rate.
Studies reporting short-term follow-up, particularly among younger cohorts of women, may overestimate the benefits of ablation.

Pain was a problem for some women. It either developed de novo after MEA or was due to preexisting dysmenorrhoea that did not resolve after treatment, even though MEA was successful in curing or reducing heavy menstrual blood loss. Possible explanations are the presence of undetected adenomyosis and the regeneration or incomplete destruction of the endometrium, particularly in the cornual regions of the uterus. This might be responsible for the development of pockets of trapped blood in the cornual region or the fallopian tube [18]. The treatment is usually hysterectomy.

These findings confirm that in suitable patients, MEA should be offered as first-line treatment for menorrhagia, along with medical management. Withholding endometrial ablation until after the failure of medical treatment should be discouraged; this may result in less satisfaction than would otherwise have been achieved had the endometrial ablation been offered to women who were not keen to be treated medically $[19,20]$.

\section{Conclusion}

For the majority of women experiencing heavy and painful menstrual blood loss and who are anxious to avoid hysterectomy whenever appropriate, a $77 \%$ success rate and a quick recovery with very few complications make MEA a valuable treatment option.

Most respondents in this survey expressed their longterm satisfaction with MEA. For some, it has had a major impact on their health and quality of life. However, for a small number, MEA has had no effect on their symptoms, and in a very few it resulted in new side effects.

We recommend providing more information, both verbal and written, before the operation. Including patient quotes in the information leaflets as "statements of satisfied patients" might be more beneficial than simply relying on figures and success rates quoted from quantitative research studies. Patients who make their own informed choices about their treatment are likely to be more satisfied. Physicians should be able, whenever appropriate, to offer MEA as first-line treatment for heavy menstrual blood loss, particularly since medical treatment is known to be less effective and some women may be concerned about its side effects.

Follow-up appointments may provide an opportunity to discuss any side effects and to evaluate any residual problems. However, their cost-effectiveness and impact on patient satisfaction is doubtful. To allow more efficient use of time and resources, it might be more appropriate to arrange follow-up appointments only for the small percentage of patients who did not benefit from MEA or who experience pain after the operation. 


\section{References}

1. Chimbira TH, Anderson ABM, Turnbull AC (1980) Relation between measured blood loss and patient's subjective assessment of loss, duration of bleeding, number of sanitary towels used, uterine weight and endometrial surface area. Br J Obstet Gynaecol 87:603-609

2. Royal College of Obstetricians and Gynaecologists (1998) National evidence-based clinical guidelines: the initial management of menorrhagia. Guideline no. 1. RCOG Press, London

3. Royal College of Obstetricians and Gynaecologists (1999) National evidence-based clinical guidelines: the management of menorrhagia in secondary care. Guideline no. 5. RCOG Press, London

4. Chi IC, Farr G (1994) The non-contraceptive effect of levonorgestrel-releasing intrauterine device. Adv Contracept 10:271-285

5. Henshaw R, Coyle C, Low S, Barry C (2002) A retrospective cohort study comparing microwave endometrial ablation with levonorgestrel-releasing intrauterine device in the management of heavy menstrual bleeding. Aust N Z J Obstet Gynaecol 42 (2):205-209

6. Sharp NC, Cronin N, Feldberg I, Evans M, Hodgson DA, Ellis $\mathrm{S}$ (1995) Microwaves for menorrhagia: a new fast technique for endometrial ablation. Lancet 346(8981):1003-1004

7. Hodgson DA et al (1999) Microwave endometrial ablation: development, clinical trials and outcomes at three years. $\mathrm{Br}$ J Obstet Gynaecol 106:684-694

8. National Institute for Clinical Excellence (2004) Fluid-filled thermal balloon ablation techniques for heavy menstrual bleeding. Technology appraisal no. 78. NICE, London

9. Crow R, Gage H, Hampson S et al (2002) The measurement of satisfaction with healthcare: implications for practice from a systematic review of the literature. Health Technol Assess 6 (32): $1-244$
10. Gannon MJ, Day P, Hammadieh N, Johnson N (1996) A new method for measuring menstrual blood loss and its use in screening women before endometrial ablation. $\mathrm{Br} \mathrm{J}$ Obstet Gynaecol 103:1029-1033

11. Hurskainen R, Teperi J, Turpeinen U et al (1998) Combined laboratory and diary method for objective assessment of menstrual blood loss. Acta Obstet Gynecol Scand 77:201-204

12. Coulter A, Peto V, Doll H (1994) Patients' preferences and general practitioners' decisions in the treatment of menstrual disorders. Fam Pract 11:67-74

13. Lampling DL, Rowe P, Clarke A, Lethaby A (1998) Development and validation of the menorrhagia outcomes questionnaire. Br J Obstet Gynaecol 105:776-779

14. Shaw RW, Birckly M, Evans L, Edwards M (1998) Perceptions of women on the impact of menorrhagia on their health using multi-attribute utility assessment. Br J Obstet Gynaecol 105:1155-1159

15. Clark TJ, Khan KS, Foon R, Pattison H, Bryan S, Gupta JK (2002) Quality of life instruments in studies of menorrhagia: a systematic review. Eur J Obst Gynecol Reprod Biol 104: 96-104

16. Youngman MB (1987) Designing and analysing questionnaires. University of Nottingham School of Education, Nottingham

17. Myer WR et al (1998) Thermal balloon and roller ball ablation to treat menorrhagia: a multicentre comparison. Obstet Gynecol 92:98-103

18. Bae IH, Pagedas AC, Perkins HE, Bae DS (1996) Postablationtubal sterilisation syndrome. J Am Assoc Gynecol Laparosc $3: 435-438$

19. Cooper KG, Parkin DE, Garret AM, Grant AM (1999) Two year follow-up of women randomised to medical management or TCRE for heavy menstrual loss: clinical and quality of life outcomes. Br J Obstet Gynaecol 106:258-265

20. Cooper KG, Jack SA, Parkin DE, Grant AM (2001) Five year follow-up of women randomised to medical management or TCRE for heavy menstrual loss: clinical and quality of life outcomes. Br J Obstet Gynaecol 108:1222-1228 